\title{
Ensaio Cidadania e civilização tecnológica: a mudança de quadros conceptuais em formação e educação
}

Joaquim Coelho Rosa

O modelo conceptual e prático com que, durante séculos, a nossa civilização se regeu era inseparável da distinção entre "ciência" e "técnica". 0 momento em que nos encontramos, momento em que, por um lado, "ciência" e "técnica" vieram a constituir uma unidade indissolúvel e em que, por outro lado (que é, talvez, apenas um outro aspecto do mesmo acontecimento), tal unidade fez com que a civilização deixasse de ser "nossa" e se tomasse global, obriga necessariamente a repensar os tópoi da "ciência" e da "técnica" e da nossa relação com elas.

Ciência e técnica, com os seus papéis diferentes, tinham também "tempos" diferentes. Aliás, e porque se trata de repensar os tópoi da ciência e da técnica, é preciso ter em conta que o tópos não é, em grego clássico, um conceito meramente espacial, mas sim um conceito "eco-lógico". O tópos de uma coisa é o seu "lugar" de implantação na existência, isto é, num espaço/ tempo do todo do mundo. 0 tópos é um conceito "eco-lógico", porque assinala que o logos de uma coisa, a sua razão de ser, coloca-a num "lugar" espaço/ temporal que lhe é próprio, a sua "casa-no-mundo" (oik os). 
Convirá, ainda que de forma estilizada, traçar um quadro de compreensão das relações "tópicas" entre o que chamamos "ciência", "técnica" e "prática", entendendo que, na ordem do discurso compreensivo, os tópoi são os reveladores, por assim dizer em negativo, dos tópoi na realidade mundana. A formação e a educação são realidades humanas em que, por excelência, cruzam-se "ciência", "técnica" e "prática" e requerem, por isso, revisão.

\section{A ciência e a técnica}

Tradicionalmente, "ciência" e "técnica" teciam entre si uma relação de anterior/ posterior. Era uma matriz proveniente dos gregos, nomeadamente de Aristóteles, que a sistematizou, sobretudo na M etafísica e na É tica a N icómaco실 com a distinção dos saberes (epistémai) em "teoréticos", "técnicos" e "práticos".

Segundo essa distinção, os saberes teoréticos conheceriam as causas eas razões, os saberes técnicos, conheceriam as aplicações, que incorporavam de forma implí cita as causas e as razões teoréticas, e os saberes práticos organizavam as acções e os comportamentos consequentes e coerentes com as causas e as razões teoréticas e com os instrumentos técnicos e operativos.

A implantação e o desenvolvimento dessa matriz conceptual originou um modelo civilizacional, conceptual e prático, segundo o qual cabia à ciência um papel essencialmente criativo, inventivo e inovador (donde a sua articulação indissolúvel com a investigação) eà técnicaum papel repetitivo e multiplicador dos processos eficazes.

Ciência e técnica, com os seus papéis diferentes, tinham também "tempos" e "espaços" diferentes. Perante qualquer "objecto" (fenómeno, problema... ), à ciência caberia a compreensão causal e a integração num contexto global de sentido e de coerência. Um novo "objecto" origina uma deslocação de todo o horizonte em que emerge, provocando, por vezes, 0 bascular de todo o campo axiomático.

Na posse de um novo saber, vinha 0 tempo da divulgação, do debate, do confronto do novo saber com os velhos saberes. Em geral, era também o tempo de maturação da pergunta "o que fazer?" com o novo saber adquirido. A pertinência do novo saber era confirmada ou infirmada, sobretudo pelos efeitos "pragmáticos" (de tipo técnico ou prático) a que dava origem. Poderia acontecer, por vezes, que uma descoberta "técnica" originasse investigação e fundamentação científicas. Mas só quando estas se realizassem é que a descoberta "técnica" ficaria legitimada. Antes disso, era concebível apenas como fruto de um acaso feliz.

Um avanço na "ciência", uma descoberta, tinha, assim, dois sucedâneos, oriundos da pergunta "o que fazer com 0 novo saber?": um "técnico", pela introdução de novos instrumentos de resposta aos estímulos e às necessidades ou pela criação de novos artefactos; um "prático", pela eventual adopção de novos comportamentos decorrentes quer do novo saber quer dos novos instrumentos e artefactos. Estilizadamente, diríamos que, a uma inovação científica, se seguiriam dois tipos de repetição fundamentada, um técnico e outro prático.

Um exemplo simples deste modelo estilizado pode ser o do telefone. A descoberta "científica" da acumulação e controlo da energia permitiram a construção de um aparelho "técnico" de envio e captação do som a distância, que originou uma mudança na acção "prática" dos homens, a ponto de ter quase acabado com um género 
cultural e civilizacional, importantíssimo ao longo dos séculos, o género epistolar, que moldava, realmente, os modos de viver, sentir e ser.

Embora estilizado, o modelo descrito vigorou durante séculos. No fundo, é 0 modelo hipotético-dedutivo, que, ao contrário do que normalmente se escreve e ensina, não remonta à ciência moderna, mas sim a Platão 2 . É um modelo que tem suposto que, sobre a base de alguns princípios teoréticos, aceites universalmente como necessários, podem-se deduzir "teoremas", válidos quer na ordem teorética, quer na técnica, quer na prática.

Em termos educacionais, todos temos facilmente presentes os modelos a que deram origem: modelos de primado do saber, ou seja, modelos segundo os quais o saber científico é objectivo e necessário, de forma absoluta e universal; e modelos de primado do ensino, que são, em geral, avatares dos primeiros, e segundo os quais, em matéria educacional e dado que o saber é objectivo, absoluto e universal, os procedimentos educativos são sobretudo os que respeitam ao modo como o saber se transmite de quem 0 tem para quem 0 não tem.

Essas compreensões paradigmáticas originaram igualmente um modelo de "escola" ainda vigente e que, também ele, remonta à Academia de Platão. É uma escola estruturada em nome de um saber objectivo, absoluto e transcendente (as Ideias) que alguns iluminados (os mestres) têm por missão recolher e oferecer aos pobres prisioneiros da caverna (os alunos).

Esse tipo de partilha confirma e reconduz os próprios pressupostos de que parte. Saber, ensino e aprendizagem têm 0 mesmo "objecto", mas cada classe apropria-o de modo diferente: uns produzemno, outros repetem-no. E, destes, uns repetem activamente (os mestres), outros repetem passivamente (os alunos), o que origina todo um jogo de classes educacionais: a dos "científicos", contempladores e produtores do saber; a dos "técnicos", repetidores e distribuidores do saber produzido pelos "científicos"; e a dos "alunos", que, no fim da cadeia (ou, brincando com as palavras, dentro dela), prestam contas de todo um processo em queé suposto serem apenas sujeitos passivos.

Obviamente, trata-se de um esquema de representações e de estabelecimento de instituições e de processos em que ficam separadas e hierarquizadas, racional e praticamente,
"Saber, ensino e aprendizagem têm o mesmo 'objecto', mas cada classe apropria-o de modo diferente: uns produzem-no, outros repetem-no. $E$, destes, uns repetem activamente (os mestres), outros repetem passivamente (os alunos), o que onigina todo um jogo de classes educacionais" .

posições e funções. Saber, fazer e agir sucedem-se numa ordem decrescente de importância 0 saber-fazer e mesmo o saberagir (ou saber-ser) eram mais ou menos meritórios consoante brotavam ou não de um saber conceptualizado.

No fundo, o suposto era de que seria possível separar os efeitos das causas. Assim, os detentores do saber conceptual 
(científico, político, religioso... ) estavam habilitados com 0 saber e o poder das causas. Aos outros ficava o suportar os efeitos. 0 esquema é sempre o mesmo: é o saber conceptual que descobre, cria, inova e comanda; agir e operar significam ouvir, reiterar, repetir e obedecer.

Não são precisos muitos exemplos para mostrar como este esquema vigorou e ainda vigora: a "superioridade" do ensino académico sobre o "técnico"; a "superioridade" dos últimos níveis do sistema educativo sobre os primeiros; a divisão nas instituições, mesmo (sobretudo?) nas do saber, entre os que mandam e os que obedecem; o suposto que, mesmo na ordem ética, 0 agir bem consiste em agir de acordo com as regras "objectivas" e "absolutas" definidas pelos "superiores", mesmo que quem obedece não veja qualquer razão para assim proceder. $\mathrm{N} 0$ fundo, a questão do saber na nossa civilização tem sido sempre uma questão de poder"

\section{A civilização tecnológica}

É toda esta estilização que acabou por ruir. Não que os espíritos mais atentos não tenham sempre alertado para o facto de não ser possível estabelecer cesuras tão claras entre os diferentes planos da vida individual e da vida institucional. Mas 0 esquema foi conservando uma certa operatividade durante séculos.

Não é por acaso (embora não seja fácil nem venha aqui ao caso determinar relações de causalidade) que a ruína de toda essa estilização civilizacional tenha acontecido ao mesmo tempo em que aconteceu a mais extraordinária revolução da disseminação da informação e do conhecimento. Creio que os dois fenómenos são apenas duas faces (enão as únicas) do mesmo acontecimento.

Com efeito, o surto quantitativo e qualitativo de desenvolvimento dos instrumentos e suportes da informação e do conhecimento pulverizou o hiato "tópico" entre o espaço/ tempo da produção do saber e o espaço/ tempo da "pragmática" (técnica ou prática). Hoje em dia, todo o saber (logia) é, ipso facto, exercício e utilização de instrumentos metodológicos efuncionais, isto é, desempenho "técnico".

A ciência é, de ponta a ponta, exercida "tecnicamente" e a "técnica" é, toda ela, impregnada de ciência, a tal ponto que só sabe-fazer quem sabe e só sabe quem sabefazer. É a essa fusão entre "ciência" e "técnica" que se chama "tecno-ciência" ou tecnologia. E, se é verdade que, em certo sentido, toda a "técnica" foi sempre uma tecnologia (sucedânea da ciência), hoje em dia, porém, o carácter a posteriori da técnica desapareceu e, com ele, o carácter de sucedânea da ciência. É toda a vida humana que se toma "tecno-lógica".

A identidade pragmática entre saber e fazer (técnico ou prático) tomou os actuais humanos quase-divinos, já que foi sempre apanágio dos deuses essa capacidade de criar (fazer-ser), exclusivamente graças à sua capacidade de conceber. Ora, isso é o que acontece com os actuais humanos, pelo menos os que usufruem dos principais benefícios da civilização tecnológica, sobretudo os mais jovens, que, desde que nascem, têm uma enorme disponibilidade de instrumentos de informação e de conhecimento, bem como de instrumentos que os capacitam para obter efeitos imediatos e a distância. E mesmo os que não dispõem desses meios de eficácia real dispõem da sua representação (graças, por exemplo, à televisão), isto é, se não têm esses poderes de facto, têm, no entanto, algo ainda mais poderoso, que é 0 "imaginário" desses poderes.

Praticamente ninguém estava preparado para tanto poder. Como lidar com ele? Não andaremos a lidar com instrumentos novos segundo lógicas de 
instrumentos antigos? Não andaremos a viver realidades novas com organizações conceptuais de realidades definitivamente ultrapassadas? Não estaremos todos a brincar aos aprendizes de feiticeiro? A educação e a formação podem continuar a conceber-se e a praticar-se sem ter esse tópico como critério essencial e determinante? 0 que é hoje o imaginário infantil e juvenil? Como se expressa? Como se organiza e como organiza a experiência em conhecimento? Que nexos tece ou pode tecer com 0 imaginário dos adultos?5

Sobretudo, que novas relações se estabele œm entre 0 saber e o poder? Essa será, talvez, a razão pela qual, sem mesmo conhecerem os fundamentos e o porquê, tanta gente fala hoje, infelizmente demasiado e a despropósito na maior parte das vezes, em "educação para a cidadania", como se fosse possível falar disso sem, primeiramente, pensar seriamente sobre "cidadania".

\section{A cidadania}

O conceito de "cidadania" está na nossa história conotado ou com a compreensão platónica da "pólis" ou com a compreensão romana da "civitas". Segundo aquela, cidadania respeita essencialmente à governação; segundo esta, cidadania respeita essencialmente à religio, ou compromisso cultural de partilha e acatamento das instituições estabelecidas (0 direito, 0 culto da cidade e dos seus deuses, a veneração do imperador, etc.). Num e noutro caso, "cidadania" confunde-se com o exercício e/ ou a participação no poder.

É nessas duas fontes que quer o liberalismo quer as democracias parlamentares beberam a sua inspiração. 0 primeiro acentuando "negativamente" o direito de autonomia e protecção dos indivíduos perante os abusos do poder; as segundas privilegiando "positivamente" o acesso de todos os indivíduos ao exercício do poder. Esta é, certamente, uma das causas principais por que se reduz (pois é, defacto, uma reducão) tão frequentemente 0 conceito de "cidadania" ao de "civismo" ou ao de "participação nas instituições". Radicam aí decerto as reinantes tirania do direito e tirania da democracia: como se as conformidades à lei ou ao voto legitimassem, só por si, o exercício do poder; como se o nazismo não tivesse chegado ao poder pelo voto; como se o III Reich ou a ex-União Soviética ou a república islâmica do Afeganistão talebano não fossem também estados de direito ${ }^{6}$.

Uma concepção de cidadania que não triunfou no 0 cidente foi a de Aristóteles, talvez por ele ser um "mestiço", um "bárbaro", em suma um "imigrado macedónio" na elitista terra dos gregos. Segundo Aristóteles, e contrariamente a Platão, para quem, no fundo, só os governantes eram verdadeiramente cidadãos, "a cidadania é a comparticipação de todos os cidadãos" 7 , e isto anteriormente à colocação da própria questão do poder ou da governação. Cidadão, diz Aristóteles, é aquele que quer governar e quer ser governado consoante o tempo oportuno que lhe couber'.

Mas não é por ter essa relação potencial ao poder ou à governação que 0 cidadão é cidadão. Ser cidadão é uma "condição de natureza": nasce-se cidadão como se nasce com cabeça, tronco e membros, mamífero, com o polegar oponível aos outros dedos, apto para assumir a posição erecta, para pensar, amar e ser livre. Esse é o significado da famosa definição (a única que Aristóteles dá a "homem") segundo a qual o homem é por natureza um animal político, zoón politikón ${ }^{9}$. 0 adjectivo "político" a ser entendido ao modo bem aristotélico (isto é, substantivo e 
não adjectivo), como a marca que identifica o polités, o cidadão.

A ristóteles sublinha mesmo que 0 homem é não um "animal gregário"10, mas sim verdadeiramente um "animal político", porque só ele "tem palavra discursiva"11. Aliás, essa era também a posição de Sófocles, que não era nem mestiço, nem bárbaro, nem imigrado macedónio ${ }^{12}$. 0 que significa que, nessa concepção que ficou "rejeitada", a cidadania era tão fundante da "hominidade" como o "corpo" (animal) ou a "alma" (racional).

A compreensão aristotélica (ou sofocleana) de "cidadania" poderia traduzir-se melhor por "socialidade", significando que os humanos, logo à nascença e contrariamente ao que sempre foi ensinado, não são "animais racionais", mas sim "animais racionais sociais". O s humanos não nascem indivíduos para, "depois", se socializarem (como se diz que cabe à escola fazer). Bem pelo contrário, os humanos nascem já sociais e a educação é a construção da sua individualidade, certamente nunca absoluta, pois, como já Aristóteles disse ${ }^{13}$, alguém que fosse naturalmente apolités seria "subumano" ou "sobre-humano", mas não seria humano.

O conceito de cidadania terá, por isso, a mesma ex tensão (mas não a mesma comprensão) que o conceito de "hominidade": só os humanos são cidadãos e, se algum animal racional estiver despojado de cidadania, estará colocado abaixo da sua condição. O conceito de "cidadania" remete para a condição ontológica dos humanos, não para a sua condição "jurídica" ou para a sua condição "política" ou para qualquer outra condição ôntica. Nesse sentido, cidadania éessencialmente a estrutura humana de "existir-com".

A tradição, tendo reduzido os humanos à dualidade corpo/ alma, reduziu quer a cidadania quer a política. Com efeito, reduziu a socialidade humanaà gregariedade, como se os humanos fossem simplesmente mais uma espécie de animal vivendo em rebanho, em bando, em matilha, em cardume ou noutra qualquer forma de "substantivo colectivo". Com isso, conseguiu reduzir a socialidade a uma questão de "poder", fazendo decair (sem conotação moral, mas apenas no sentido de reduzir algo mais lato a algo mais restrito) o "cívico" para o "político". Operada essa redução, restava só colocar a pergunta: "quem manda no rebanho?". A estrutura ontológica do "ex istir-øm" está historicamente reduzida à questão política do "poder-sobre".

\section{Questões}

- Na perspectiva aqui exposta, a nova civilização tecnológica cuja configuração mais visível se chama "globalização" éumaameaça para as democracias e para o seu exercício da soberania. As democracias/ soberanias parecem completamente incapazes de a si mesmas se reconduzirem ao seu fundamento de cidadania. Os poderes, os "soberanos", sentem-se naturalmente ameaçados pela civilização tecnológica, pois estatem, de facto, um potencial imenso de igualização do saber (e, portanto, do poder), reduzindo o espaço/ tempo das hierarquias tradicionais. Na realidade, as democracias vivem segundo um modelo organizacional de "soberania do Estado", quando, de iure e de facto, em democracia, a soberania reside na $\mathrm{N}$ ação, isto é, nos próprios cidadãos.

- O ra, "cidadania" é mesmo um conceito "global", comum à "hominidade", visto que respeita à própria condição essencial da existência dos humanos. Em muitos sentidos essenciais, a globalização tecnológica é, por isso, uma das grandes oportunidades da "hominidade" e da cidadania, ao contrário do que se quer, por 
vezes, fazer crer. O s poderes políticos constituídos servem-se dela como álibi para a sua permanente desresponsabilização; e os adversários da globalização tecnológica culpam-na dos erros da civilização anterior, erros que, pelo contrário, sobretudo ela poderá ajudar a resolv er.

- O que acaba de ser dito não significa que a globalização tecnológica seja um acontecimento historicamente puro, uma espécie de "amanhã (hoje) que canta". Como todas as mudanças de civilização, a globalização tecnológica será o que os humanos delafizerem. As suas virtualidades são as melhores que alguma vez se depararam aos humanos: trazendo o triunfo das sociedades do conhecimento, a globalização tecnológica traz o que justifica a esperança no que serão as mais humanas de todas as sociedades até hoje realizadas, "super-humanas" relativamente às sociedades do passado: só os que forem "tecno-logicamente" competentes continuarão a ser humanos, isto é, capazes de ser e existir à escala do global.

- A supressão do hiato "tópico" entre saber e fazer (técnico ou prático), ao suprimir o espaço/tempo onde se colocava a questão "o que fazer?", eliminou 0 tópos das morais. Estas deixaram de ser um espaço/ tempo de mediação, tornando-se, por isso, realmente impossíveis como critério absoluto da ordem prática. No espaço/ tempo em que se inseria a pergunta "o que faz er?" nem sequer ficou um vazio. Pura e simplesmente, não ficou nada, porque esse espaço-tempo desapareceu e, quando se pergunta "o que fazer?" com um novo saber, verificamos que já está feito, que ficou feito ao fazer-se o próprio saber ${ }^{14}$.

- Qual, então, a lógica e até a simples possibilidade de continuar a educar e a formar para a acção, para a profissão, para os valores? Será que ainda é possível formar para... ? A falta de tópos das morais implica a aceitação da impossibilidade de procurar e receber sentido, ou obriga a inventar um novo tópos, digamos que ético e não-moral, em que o sentido não esteja como um dado, mas antes como algo a construir?

- Se todo o saber é um fazer e viceversa, não implica isso que todas as nossas relações com as instituições e as próprias instituições têm de ser refeitas? As instituições (todas as instituições, as políticas, as religiosas, as científicas, as empresariais, etc.) estão criadas e montadas como meios para fins que deixaram, uns e outros, de ser válidos. A concepção e a execução

\section{"Qual, então, a lógica e até a simples possibili- dade de continuar a educare a formar para a acção, para a profissão, para os valores? Será que ainda é possível formar para... ?}

deixaram de ser instâncias e processos separados. Como continuar a ter e a criar sistemas cuja organização consiste em colocar em cena actores que supostamente devem fazer coisas que não podem fazer?

- Cenas que não existem, actores que não podem desempenhar o papel que lhes é atribuído, enfim sistemas cuja única coerência, que, por isso, faz a unanimidade, é não terem qualquer função nem qualquer eficácia? Não será essa a razão pela qual, seja qual for a instância educacional em que nos situemos (política, científica, técnica, administrativa), só o conceito de "sistema educativo" é um conceito unívoco? Não 
será porque éjustamente um conceito vazio sem realidade adequada ou sequer possivel? Q ue, se fosse sistema, não seria educativo e, se for educativo, não pode ser sistema? Não seria indispensável acabar com os chamados Ministérios da Educação, instâncias "técnicas" de mediação entre 0 político e 0 científico-pedagógico, absolutamente inadequadas numa civilização tecnológica?

- No que respeita ao pedagógico propriamente dito, o mínimo que se pode dizer é que deixou de ser "propriamente dito". O pedagógico só é concebível hoje em dia como científico-pedagógico, entendido igualmente o "científico" no contexto de sentido que se deu ao "tecno-lógico". Aprender não é, hoje, repetir e reiterar os conhecimentos produzidos por via científica e mediatizados por via técnica. Aprender ére produzir, recriar, saber a partir daquilo que faz a própria existência e dos próprios actos da vida. Todo o esforço da interdisciplinaridade é ainda ilusório e inglório. 0 saber étrans-disciplinar, implantado numa realidade "tópica" que se encontra aquém, para além e atravessando as disciplinas, todas as disciplinas.

- Como continuar a separar "saber" e "expressões"? Como continuar a concebê los sequer como complementares quando, na prática, são a mesma coisa? Como dividir entre expressão da pessoa e compreensão e intervenção no mundo? Como continuar a dividir arte (techné) e ciência? Como continuar a dividir saber-ser, saber-fazer e saber? Ser capaz de construir saber não será, essencialmente, saber-ouvir, saber-ver, saber-tocar, saber-ser-0-seu-corpo, saberestar-no-mundo? Conhecer o mundo não será essencialmente tornar-se pessoa? E tudo isso não significará que a chave do desenvolvimento e do conhecimento está nas crianças e nos jovens e não nos preconceitos dos doutores e dos técnicos?

Todo esse conjunto de reflexões e perguntas não é mais do que isto: reflexões e perguntas. 0 desafio do tempo presente não tem medida comum com os nossos conceitos e práticas habituais. Não vale de nada apelar ao senso comum (a que alguns chamam, não sei com que fundamento, "bom-senso"), para esconjurar a urgência de ousadia que nos é imposta pelas circunstâncias que nós próprios criámos.

0 mundo em que vivemos e que nós, humanos, criámos não tem nada que ver com o senso comum que se foi cimentando durante séculos. Esse senso comum ainda será comum, ou largamente comum, mas é tudo menos "sentido" (senso). Persistir nele é, pura e simplesmente, um contra-senso que nos empurra para 0 abismo. E irmos em comum para o abismo não é melhor do que irmos um a um: para todos os efeitos conceptuais e operativos, é exactamente a mesma coisa.

(Texto recebido em junho de 2005. Versão definitiva em agosto de 2005)

\section{Notas}

${ }^{1}$ Metafísica, A, 1, 980 a 1 - 982 a 2; Ética a Nicómaco, VI, 2-4, 1139 b 14 - 1140 b 8. O s textos de Aristóteles são referidos a partir do grego Aristotelis graece, ex recensione IMMANUELIS BEKKERI, ed. Acad. reg. Borussica, Berlim, 1831-1870. 
${ }^{2} \mathrm{O}$ "mito da caverna" é proposto, por Platão, como uma hipótese. Logo na primeira linha de 514 a, no início do Livro VII da República, Platão convida a "imaginar uma cena" , a fantasiar uma situação. E, em 517 b, fazendo a interpretação do mito, afirma expressamente que este é uma especulação sua e que "o D eus sabe se ela é verdadeira”. A hipótese platónica só é tomada como uma tese porque, segundo o desenvolvimento que Platão faz, na República, a seguir à narrativa do mito, este se revela operativo, isto é, organiza e faculta uma compreensão vero ssímil das aporias suscitadas desde o princípio do diálogo até ao Livro VII. As referências à República são feitas pela tradução portuguesa de Maria Helena da Rocha Pereira, Fundação Calouste Gulbenkian, 8 a ed., Lisboa, 1996.

${ }^{3}$ Metafísica, A, 1, 981 a 28, 981 b 6, 982 a 1.

${ }^{4}$ Os famosos Ensaios de Montaigne, sobretudo o ensaio sobre o "professorado" e o ensaio sobre "a educação das crianças", são os primeiros textos que, com enorme lucidez, põem em relevo e questionam esta herança.

${ }^{5}$ COELHO RO SA, Joaquim. Investigação e educação. Lisboa: Escola Superior de Educação João de D eus, 1994.

${ }^{6}$ Giorgio Agamben mostra como liberalismo, democracia, nazismo, fascismo e estalinismo partilham uma racionalidade comum, cuja af inidade é inquietante. AGAMBEN, Giorgio, Homo Sacer, Giulio Einaudi Editore sp.a., Torino, 1995 (trad. port. O Poder Soberano e a Vida Nua, Editorial Presença, Lisboa, 1998).

${ }^{7}$ Política, VII, 13, 1332 a 34-35.

${ }^{8}$ Política, III, 13, 1283 b 43 - 1284 a 3.

${ }^{9}$ Política, 1253a 1-7.

${ }^{10}$ Como pretendia Platão: República, 520 b.

${ }^{11}$ E não porque é "racional", como a tradição traduziu. Ver Política, 1253 a 7-10.

${ }^{12}$ Ver Antígona e o seu famoso coro sobre o "homem".

${ }^{13}$ Política, 1253 a 4.

${ }^{14}$ Coelho Rosa, Joaquim. Ética profissional no serviço público. Brasília:Ministério do Planejamento, 2005.

Joaquim Coelho Rosa

Pesquisador da Unidade de Pesquisa em Educação e D esenvolvimento da Faculdade de Ciências e Tecnologia da Universidade Nova de Lisboa e vice-presidente da Civitas, Associação para a Promoção e D efesa dos D ireitos do Cidadão (Portugal), entidade filiada à Fédération Internationale des D roits del'Homme (FID H). Contato: <jcoelhorosa@ oninetspeed.pt>. 


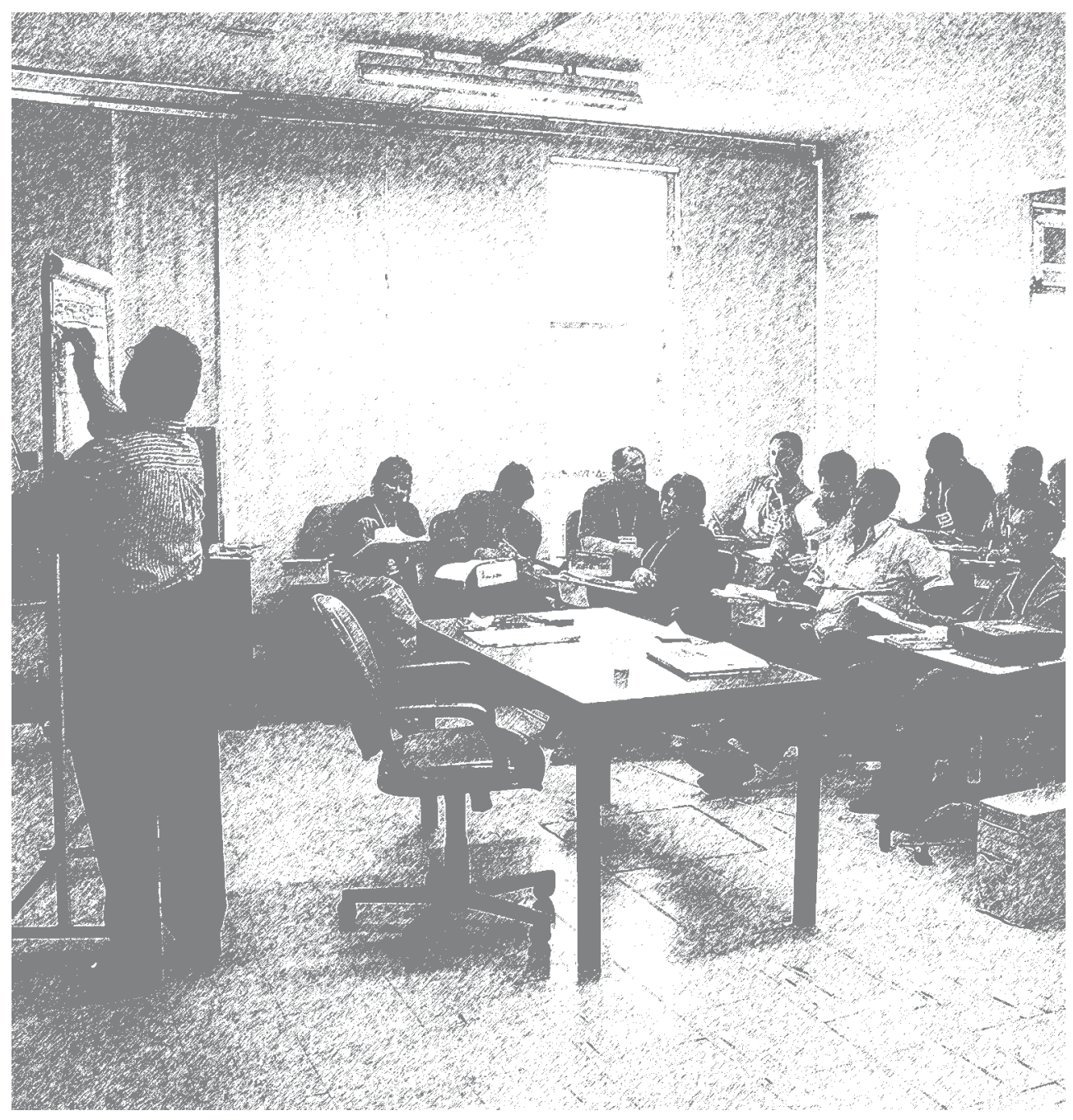

